\title{
A new Standard for Doing Agile Scrum Team Work in Education
}

\author{
Author(s) \\ Loke, Rob \\ Publication date \\ 2020 \\ Document Version \\ Author accepted manuscript (AAM)
}

Link to publication

Citation for published version (APA):

Loke, R. (2020). A new Standard for Doing Agile Scrum Team Work in

Education. Abstract from 8th European Conference on Education

2020. https://papers.iafor.org/submission57991/

It is not permitted to download or to forward/distribute the text or part of it without the consent of the author(s) and/or copyright holder(s), other than for strictly personal, individual use, unless the work is under an open content license (like Creative Commons).

\section{Disclaimer/Complaints regulations}

If you believe that digital publication of certain material infringes any of your rights or (privacy) interests,

please let the Library know, stating your reasons. In case of a legitimate complaint, the Library will make the material inaccessible and/or remove it from the website. Please contact the library:

https://www.amsterdamuas.com/library/contact/questions, or send a letter to: University Library (Library of the University of Amsterdam and Amsterdam University of Applied Sciences), Secretariat, Singel 425, 1012 WP Amsterdam, The Netherlands. You will be contacted as soon as possible. 


\title{
A New Standard for Doing Agile Scrum Team Work in Education
}

\author{
Rob Loke, Amsterdam University of Applied Sciences, Netherlands
}

The European Conference on Education 2020

Official Conference Proceedings

\begin{abstract}
Scrum is increasingly becoming an essential product development methodology for project education in modern curricula, however, individually assessing students that work in scrum projects as applied in the professional work field remains extremely challenging until date. In scrum, students team up in order to deliver high-quality products in projects that are directed to real business stakeholders in order to enhance professional productivity and allow for flexibility to product requirements. Our new standard adds up to this methodology in three ways. First, we propose to represent the common language that is relevant to stakeholders, product owners and development teams in terms of epic, user story and task such that team members from different backgrounds learn to comprehend together. Second, we propose a two-stage task allocation approach in which, first, learning outcomes for a course that are set in education designs are preliminary mapped by the lecturer to abstract, state-of-the-art, tasks that are commonly relevant in the expert domain, and, then, concrete tasks for the project at hand are placed on project scrum boards by students during scrum sprint plannings in the course run. Third, we propose to assess scrum teams both at group and individual student level. For the individual grading, we define a novel concept of task balance that we consequently measure inside teams. With the aid of automated tools, the standard has been successfully applied and operationalised in various course runs of our multidisciplinary master where it has proven to be effective in assigning individual grades when needed.
\end{abstract}

Keywords: Scrum, Education, Team Work, Individual Grades, Task Balance

\section{iafor}

The International Academic Forum www.iafor.org 


\section{Introduction}

Imagine a world wherein education can take place outside education institutes in the real professional work field. Artificially created assignments for students by lecturers can be replaced by work that truly matters and that needs to be done and that pays off in the real world. Valuable human resources that are scarce in the labor market such as engineers and data scientists become earlier available to the work field. Scarcity in the labor market due to the foreseen demographic transformation in the Western society will be softened. Lifelong education initiatives will be tailored.

Scrum is an agile framework for developing, delivering, and sustaining complex products (Schwaber \& Sutherland, 2017). It is flexible, fast, low cost and allows for agility for instance. In this paper we use the original scrum framework of Schwaber \& Sutherland (2017) as a basis. This is the most applied framework in the professional work field.

Application of scrum in education has been hindered, because, in education, we often want individual grades, and, until now, this has not been possible. This is also the case for to education dedicated scrum frameworks such as eduscrum (eduscrum.nl). This ackward and unpleasant situation has now ended because with our newly developed standard that we define and build on top of the scrum framework of Schwaber \& Sutherland (2017) it now becomes possible to effectively assign individual grades to students when needed.

In this paper we firstly describe the new standard that we have developed for doing scrum in education and secondly give requirements that are needed to work with our standard. Then we give empirical results of using the standard in several courses that we run and discuss and conclude our work.

\section{Scrum teamwork}

We apply scrum as it has been defined in scrum.org (Schwaber \& Sutherland, 2017). In the text below we will assume that you are familiar with the terms that are defined in the booklet that you can find online from this reference.

\section{A new standard in education}

On top of the definition of scrum we define an additional new standard for education that is based on three conceptualisations:

1. a common language

2. a two-stage task allocation process that involves lecturers and students

3. task balance as a measure to enable individual grading

These concepts will now be described.

\section{A common language}

In the actual definition and implementation of a plan in scrum terms, a scrum/Kanban board as well as sprint planning with poker (scrum playing cards) play commonly an 
important role for the planning of workloads within a team. The activity boards can be digitally implemented and operated with various tools such as Trello or Quip.

We represent the common language that is relevant to stakeholders, product owners and development teams in terms of epic, user story and task such that team members from different backgrounds learn to comprehend together and understand each other.

The representational hierarchy of workflow in terms of epic, user story and task is common in agile, see for example van Drongelen, Dennis, Garabedian, Gonzalez, \& Krishnaswamy (2017) and Canty (2016).

For us this representation is beneficial in order to be able to define a common language in multidisciplinary teams: people from business are more likely to think in terms of epics and user stories and people from for example computer science in terms of tasks. Certainly, people that are familiar with modeling user stories and tasks on a Kanban board often feel that their board represents knowledge. Figure 1 shows an arbitrary example of epic, user story and task.

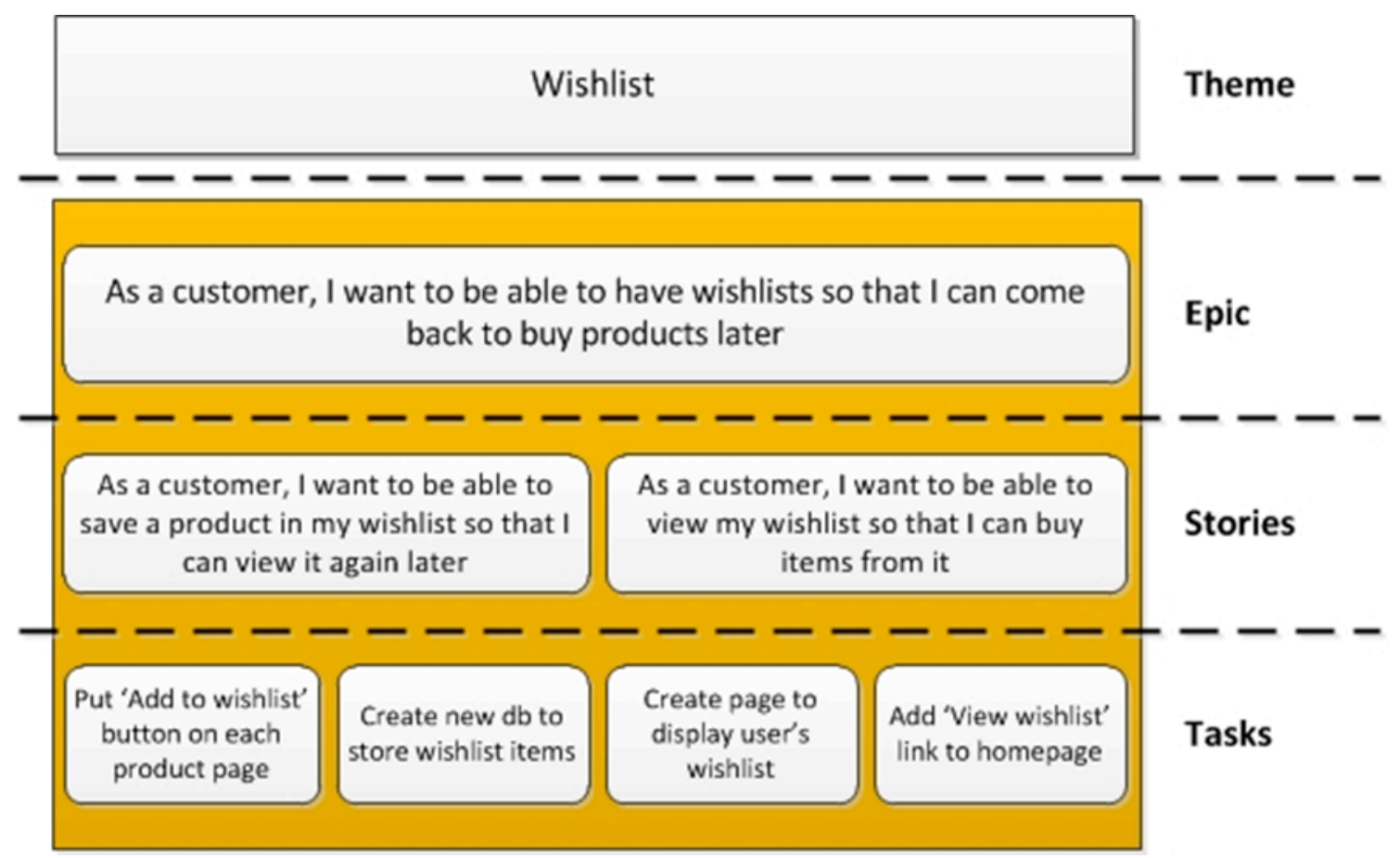

Figure 1: Decomposition of epic in user stories and tasks (copied from https://scrumandkanban.co.uk/theme-epic-story-task/).

Three example cases of epics in the expert domain of applied data science for business are given in the online presentation that accompanies this IAFOR ECE2020 paper that is available at https://vimeo.com/438418681. The epics being discussed and decomposed are:

(1) design a chatbot for a retailer

(2) develop a recommender system for company products

(3) engineer a company dashboard for corporate reputation 


\section{A two-stage task allocation process that involves lecturers and students One-stage task allocation process:}

Before defining the two-stage task allocation process we first define the one-stage task allocation process.

In the one-stage task allocation process:

- The stakeholder shares epic and, possibly, user stories in the beginning of the course.

- $\quad$ Students define concrete tasks and, possibly, user stories within their team.

- The lecturer standardises concrete tasks and classifies them into categories at the end of the course.

Sharing or not sharing user stories by the stakeholder in the beginning has an obvious effect on the perceived level of difficulty by the students.

\section{Two-stage task allocation process:}

In the two-stage task allocation process:

- $\quad$ The stakeholder shares epic (and user stories) in the beginning of the course.

- The lecturer shares abstract task categories in the beginning of the course.

- $\quad$ Students define concrete tasks (and user stories) within their team.

- $\quad$ The lecturer standardises concrete tasks at the end of the course.

Sharing abstract task categories by the lecturer in the beginning can be done in various ways, e.g., by role-playing the role of product owner who lists product requirements and features, or by listing task categories of common tasks, in readers that are preliminary available to students.

\section{Task balance within a team}

The novel concept of task balance within a team enables individual grading---besides already applicable team grading.

The idea is that the lecturer first standardises tasks according to agreed focus and relevancy at the end of the course and then counts the standardised tasks done by each team member.

Figure 2 gives an example of a reasonably balanced team. The interpretation, by the lecturer, of the purple task, is key. If that task is much more complex than a blue task, the team will be balanced. If not, the team will be unbalanced. 


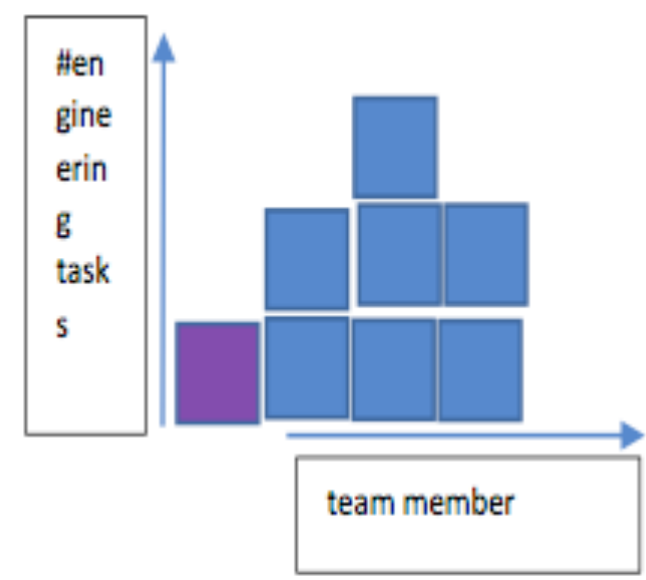

Figure 2: Example of a reasonably balanced team that requires additional interpretation by the lecturer.

Figure 3 gives an example of an unbalanced team, no matter the interpretation of the purple task.

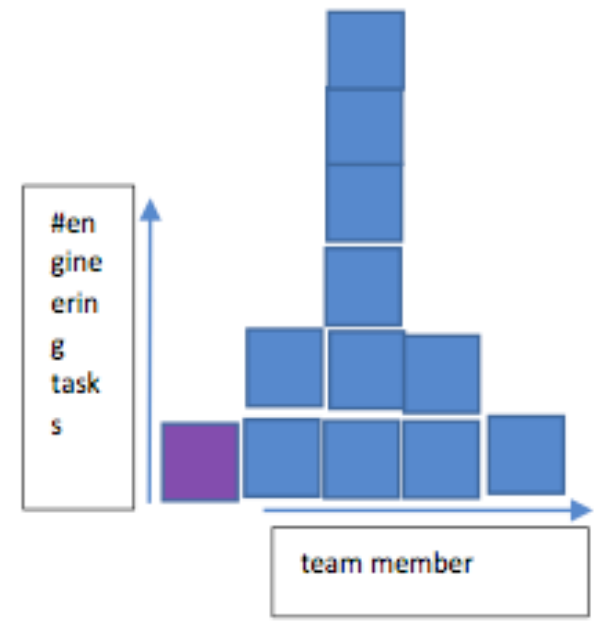

Figure 3: Example of an unbalanced team.

We now define a first, basic measure for task (un)balance:

$\mathrm{b}=\max$ number of tasks done by a student in the team / min number of tasks done by a student in the team

$b_{\min } \quad: \quad$ value under which no individual grades need to be assigned in a team

In this paper we use $b_{\min }=1.5$.

\section{Requirements}

We now list some requirements that you will need to take care of when you work with our new standard for scrum in education. 


\section{Automated team formation}

Divide the students in teams based on background. Optimise for maximum overall diversity summed over groups. The reason is that under the assumption that teams are well managed scrum works best in mixed teams.

We do automated team formation with computational algorithms. Goals are to optimise for mixed teams and to do randomization. Individual student parameters steer the algorithms to automatically form teams. One possible algorithm to do this is the one of Gallego, Laguna, Martí, \& Duarte (2013). The input parameters to the algorithm that we consider for the results presented in this paper are:

- $\quad$ Age

- Gender

- Nationality

- $\quad$ Name of bachelor degree obtained

- $\quad$ Bachelor degree type obtained: $\{$ BA, BS, BFA, BAS

- Institute name where bachelor degree has been obtained

- $\quad$ Number of years of relevant professional experience

The output parameters of the algorithm are team number per student.

\section{Clearly define roles for lecturer and students and manage expectations}

Clear definition of roles for lecturer and students and expectation management is important.

There are different topologies of doing scrum team work in education at play:

- $\quad$ Set 1 of roles: stakeholder, product owner, developer in development team

- $\quad$ Set 2 of roles: student, lecturer

- $\quad$ Set 3 of roles: scrum master

Be conscious of your role!

\section{Automated tools and derived forms}

Use automated tools and derived forms when possible.

Possible choices for automated tools are Slack for general team communication, Trello for scrumboard and related communication, and Github for (programming) task implementation and related communication.

One team grading form per team for explicit registration by students of student tasks is needed at the end of the course for the lecturer to standardise committed student tasks. This form can be streamed by the students themselves from their scrumboard. A possible choice for a digital tool that comes in handy here is for instance google docs.

\section{Empirical results}

We now give empirical results that were obtained with the standard in two different courses. Table 1 lists the different course runs with parameters for implementation of the standard (columns 2, 3 and 4) and grading results (columns 5 and 6). 


\begin{tabular}{|c|c|c|c|c|c|}
\hline $\begin{array}{l}\text { Course run } \\
\text { (3week) }\end{array}$ & $\begin{array}{l}\text { Common } \\
\text { language used }\end{array}$ & $\begin{array}{l}\text { Task allocation } \\
\text { process }\end{array}$ & $\begin{array}{l}\text { Task balance } \\
\text { computed }\end{array}$ & Group grades & $\begin{array}{l}\text { Individual } \\
\text { refinement of } \\
\text { grades within } \\
\text { group }\end{array}$ \\
\hline $\begin{array}{l}\text { Online data } \\
\text { mining---dataset }\end{array}$ & Yes & One stage & No & Yes & No \\
\hline $\begin{array}{l}\text { Database } \\
\text { management for } \\
\text { business---design }\end{array}$ & Yes & Two stage & No & Yes & No \\
\hline $\begin{array}{l}\text { Database } \\
\text { management for } \\
\text { business---system }\end{array}$ & Yes & Two stage & Yes & Yes & Yes \\
\hline
\end{tabular}

Table 1: Multidisciplinary Master (1yr) Digital Driven Business @ Amsterdam University of Applied Sciences---2019-2020, 1st run of two courses with three deliverable products and class of 26 students.

Below, we proceed with giving separate results for each effective variant of the standard.

\section{One-stage task allocation without task balance computed}

This variant is most appropriate for experienced classes. Categorization and standardization of tasks by the lecturer is done at the end of the course. This variant results in relative team grades that are based upon relevant tasks that have been accomplished in the delivered product to the stakeholder. See Table 2.

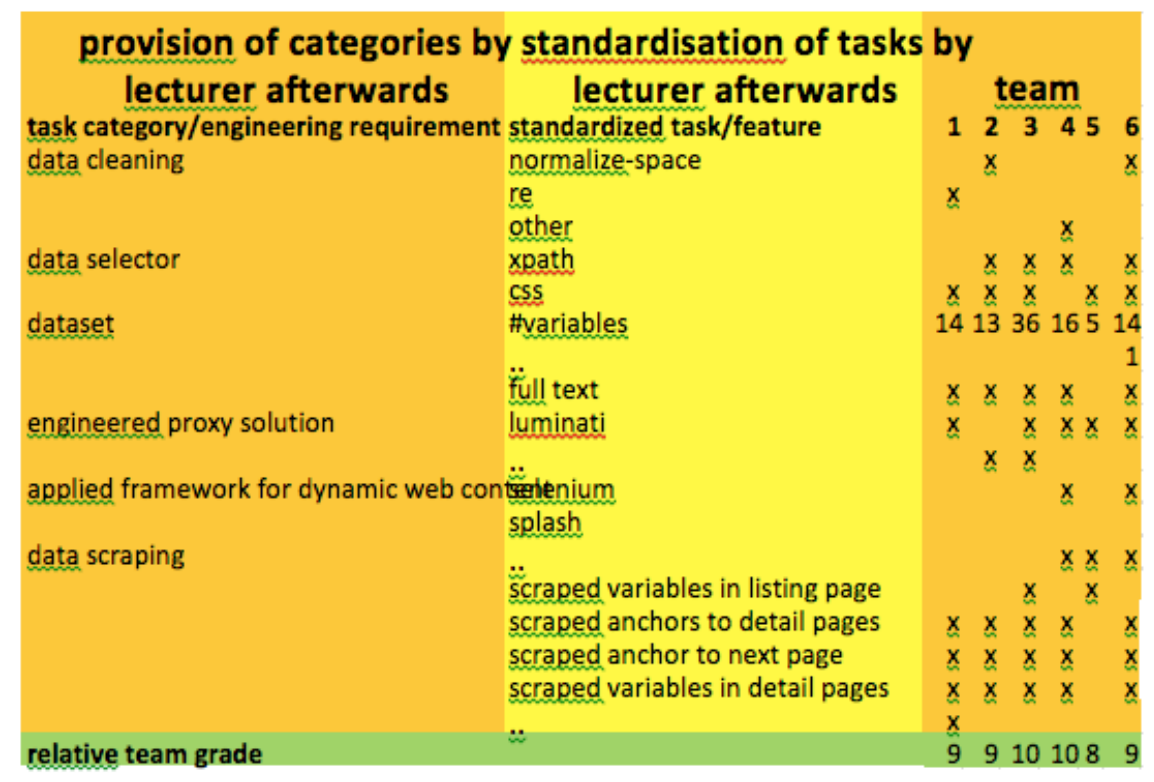

Table 2: Expert variant of standard without individual grades.

\section{Two-stage task allocation without task balance computed}

This variant is most appropriate for unexperienced classes. Categorization of tasks by the lecturer is done at the start of the course and standardization of tasks by the lecturer at the end. This variant results in relative team grades that are based upon 
relevant tasks that have been accomplished in the delivered product to the stakeholder. See Table 3.

\begin{tabular}{|c|c|c|c|c|c|c|c|}
\hline $\begin{array}{c}\text { provision of categories by lecturer } \\
\text { beforehand }\end{array}$ & $\begin{array}{c}\text { standardisation of tasks by } \\
\text { lecturer afterwards }\end{array}$ & & & & $\mathrm{m}$ & & \\
\hline task category/engineering requirement & standardized task/feature & 1 & 2 & 3 & 4 & 5 & 6 \\
\hline entity relationship (ER) diagram & comoleteness of design & $x$ & $x$ & $x$ & $x$ & $x$ & $x$ \\
\hline & simplicitx of design & $x$ & $x$ & $x$ & $x$ & & $x$ \\
\hline & Dotation specified & $x$ & & $x$ & $x$ & & $x$ \\
\hline & & $x$ & $\gamma$ & & & & \\
\hline & 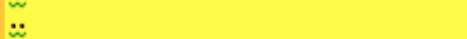 & $x$ & $x$ & & $x$ & & 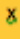 \\
\hline & 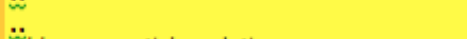 & $x$ & & $x$ & $x$ & & \\
\hline & 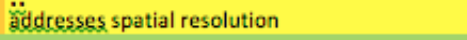 & $x$ & $x$ & & & $x$ & $x$ \\
\hline relative team grade & & 10 & 8 & 8 & 9 & 5 & 8 \\
\hline
\end{tabular}

Table 3: Rookie variant of standard without individual grades.

\section{Two-stage task allocation with task balance computed}

This variant is most appropriate for unexperienced classes. Categorization of tasks by the lecturer is done at the start of the course and standardization of tasks by the lecturer at the end. This variant firstly results in relative team grades that are based upon relevant tasks that have been accomplished in the delivered product to the stakeholder. The relative team grades obtained form a plafond for all individual team members in all teams.

This variant secondly results in individual grades within teams that are derived from the within-team computed task balances.

All individuals in a team are checked by the lecturer in the sense that individually delivered tasks relate to a minimum of required content that is needed to pass the course.

See Table 4 for the obtained results.

\begin{tabular}{|c|c|c|c|c|c|c|c|}
\hline \multirow{3}{*}{$\begin{array}{l}\text { provision of categories by lecture } \\
\text { beforehand } \\
\text { task category/engineering requirement } \\
\text { build web application }\end{array}$} & \multirow{2}{*}{$\begin{array}{l}\text { standardisation of tasks by } \\
\text { lecturer afterwards } \\
\text { standardized task/feature }\end{array}$} & \multicolumn{6}{|c|}{ team } \\
\hline & & 1 & 2 & 3 & 4 & 5 & 6 \\
\hline & & & $x$ & & & & \\
\hline & $\begin{array}{l}\text { setur data analysis framework } \\
\text { include graphics }\end{array}$ & $x$ & $\begin{array}{l}x \\
x\end{array}$ & $x$ & $x$ & $x$ & $\begin{array}{l}x \\
x\end{array}$ \\
\hline & a & & $x$ & & & & \\
\hline \multirow[t]{3}{*}{ build wrapper } & setug wrapper & $x$ & $x$ & $x$ & $x$ & $x$ & $x$ \\
\hline & a & $x$ & & & & & \\
\hline & a & $x$ & & $x$ & $x$ & $x$ & $x$ \\
\hline \multirow[t]{9}{*}{ develop sal queries } & sal query 1 & $x$ & $x$ & $x$ & $x$ & $x$ & $\mathrm{x}$ \\
\hline & sal query 2 & $x$ & $x$ & $x$ & $x$ & $x$ & $x$ \\
\hline & sal query 3 & $x$ & $x$ & $x$ & $x$ & $x$ & x \\
\hline & sal query 4 & $x$ & $x$ & $x$ & $x$ & $x$ & $x$ \\
\hline & sal query 5 & $x$ & $x$ & $x$ & $x$ & 8 & \\
\hline & sal query 6 & $x$ & $x$ & $x$ & $x$ & $x$ & $x$ \\
\hline & sal query extra & & & $x$ & $x$ & 8 & \\
\hline & saves query result & & $x$ & & & $x$ & \\
\hline & specify data types & $x$ & & $x$ & $x$ & $x$ & 8 \\
\hline enable spatial analysis & featured high spatial resolution & & & $x$ & & & \\
\hline ather categories related to developed user stories & ather tasks related to developed user stories & & & & & & \\
\hline \multirow[t]{3}{*}{ scrum parameters computed and observed } & task balance in team & $3 / 15$ & $5 / 11$ & $1 / 8$ & $3 / 1$ & $4.3 / 0.5$ & $3.8 / 0$ \\
\hline & & $3^{F}$ & 5 & 1.4 & 3 & 8.6 & ? \\
\hline & \#sprints effectively carried out & 3 & 3 & 3 & 2 & 3 & 3 \\
\hline relative team grade & & 8 & 9 & 10 & 9 & 9 & 9 \\
\hline individual team-member grades within team & & $7-8$ & $7-9^{7}$ & 10 & $7-9$ & 5-9 & $5-9$ \\
\hline
\end{tabular}

Table 4: Rookie variant of standard with individual grades. 


\section{Discussion and recommendations}

The new standard has been successfully applied in the specific expert domain of our master. The task balance that has been computed within a team allows to individually grade team members, in a natural way. The structured processes of one- and two-stage task allocation have allowed lecturers and students to register relevant tasks, at a varying level of perceived difficulty. The mental map of workload that is a result of the common language has proven to be insightful to students during product development. The provision of explicit product requirements and the implicit abstraction of tasks into categories has proven to be insightful as well.

\section{Recommendations}

Introducing scrum into your organization is not trivial. Introducing scrum as a learning paradigm is not trivial either and it takes time for lecturers and students to get familiar with it (as is the case in starting with scrum in the real work field as well). Start with two-stage task allocation for unexperienced classes and proceed to onestage task allocation for experienced classes. Stage 1 in two-stage task allocation thrives from abstract to concrete, emphasizing the crucial role of the product owner, immediately before and at the start of the sprint planning, to define explicit product requirements, in order to decrease the level of perceived difficulty. Compute task balance within a team whenever you want to allocate individual grades.

It would be interesting to see application of our standard in the education community. The standard can be applied to other expert domains, in other university studies, by other universities and education institutes, in other countries and in other languages. When you apply our new standard in your own work, please refer to this paper and our accompanying IAFOR ECE2020 presentation.

\section{Conclusion}

We promote a symbiotic world where education can take place with scrum directly in the professional work field. With this aim in mind we presented in this paper a new standard for doing scrum team work that was successfully applied in different courses to obtain grades for individual scrum team members. AFAIK, the first time ever.

\section{Acknowledgements}

First of all, all students in the 2019-2020 MSc master class of the multidisciplinary Master Digital Driven Business @ Amsterdam University of Applied Sciences for doing scrum team work with us. All colleagues @ Amsterdam University of Applied Sciences, in particular, Maartje Prevosth for discussing initial course run parameters with me. Martijn Zoet for providing initial feedback during the accreditation of our master program. Last but not least, all colleagues@ CMIHvA, Center for Market Insights, in particular, Riccardo Pinosio for running courses together with us and Frederik Situmeang for setting up courses together with me. 


\section{References}

Canty, D. (2016). Agile for Project Managers. Best Practices in Portfolio, Program, and Project Management. CRC Press.

Gallego, M., Laguna, M., Martí, R. \& Duarte, A. (2013). Tabu Search with Strategic Oscillation for the Maximally Diverse Grouping Problem. Journal of the Operational Research Society 64, 724-734.

Schwaber, K. \& Sutherland, J. (2017). The Scrum Guide: The Definitive Guide to Scrum: The Rules of the Game. URL: https://www.scrum.org/resources/what-isscrum.

van Drongelen, M., Dennis, A., Garabedian, R., Gonzalez, G. \& Krishnaswamy, A. (2017). Lean Mobile App Development: Apply Lean startup methodologies to develop successful iOS and Android apps. Packt Publishing Ltd.

Contact email: r.e.loke@hva.nl 